\title{
Can self control influence subjective well being in life? A study assessing the dynamics and association between the constructs
}

\begin{abstract}
Amina M. Qureshi ${ }^{2}$
ABSTRACT

The relationship between self-control and subjective wellbeing is an area of increasing interest for researchers in the field of positive psychology. Although numerous earlier studies have found evidence of a positive correlation between self control and several sub factors of well being such as life satisfaction, societal adjustment and social relationships, research investigating self control and well being as a distinct construct remains sparse. This study focused on researching the relationship and dynamics between self control and well being, assessing the findings with earlier studies in the area in view of the differences in society, culture and political dynamics of the location of the study and providing recommendations for enhancing self control in life. The study assessed 100 students and faculty members at an accredited university in Pakistan. Utilizing the longer version of the Ryff (1995) wellbeing scale and the full version of the Tangney, Braumeister, and Boone, (2004) self control scale, the study found a moderate correlation between self control and subjective well being, $r=$ $.583, p<0.05$. This was in line with prior studies in the field that also reported moderate to high positive associations between the two variables. The study concluded that self control positively affects well being, the results being similar and consistent across developed and developing countries and that there are specific strategies that can be utilized to enhance personal self control in life.
\end{abstract}

Adnan Khan $^{1}$

Keywords: Self control, Self regulation, Wellbeing, Happiness

\section{INTRODUCTION}

Investigating the association between self control and wellbeing is a growing concern for researchers. Although various conceptions of self control have been put forth, there is a general consensus among social researchers that self control is the ability to overpower, override or change one's responses to desires and temptations as well as to disrupt undesirable behavioral tendencies and impulses and orient oneself away from pursuing them (Hoffman, et al., 2013). As such, self control assumes a prominent role in human endeavor, achievement and wellbeing in life. People low in self control have consistently been linked to academic underachievement, substance abuse, relationship and emotional problems, behavioral issues, delinquency, poor health, and other social ailments (Duckworth \& Seligman, 2005; Friese \& Hofmann, 2009). On the other hand, people who rate high in self control measures report higher academic achievement, stronger interpersonal relationships, emotional stability, higher monetary incomes, life satisfaction and well being in life (Moffit et al., 2011).

Although studies have robustly proven the strong linkages between high self control and positive outcomes for individuals in academics, life satisfaction, and social adjustment (Stanford, \& Barratt, 1995; Vohs \& Faber, 2007), the research involving self control and well being in life is surprisingly sparse (Hoffman, et al., 2013). The few studies that have investigated the variables have found a positive relationship between the two constructs (Vohs $\&$ Faber, 2007). These results are not surprising, if people with strong self control tend to do

1- Adnan Khan is CEO at The Elation Institute, adikhannz@gmail.com

2- Amina M. Qureshi is Associate Professor at Bahria University Islamabad, aminamuzaffar_q@hotmail.com

\begin{tabular}{llll|l}
\hline JISR-MSSE & Volume 13 & Jumber 2 & July-Dec 2015 \\
\hline
\end{tabular}


well in academic achievement, personal relationships, maintain good health, have a strong sense of control and report more positive emotion, then it should automatically follow that high self control would be strongly correlated with well being in life.

There remains plenty of room for further investigation, however: first: some of the studies involving self control and its associations with human welfare focus specifically on happiness or positive emotion, which is only a subset or factor of wellbeing (Seligman, 2011), second, the practical aspect of how to enhance personal self control remains missing from a majority of studies in the area, and third, most of the studies conducted in the field were done in western developed countries with specific cultural characteristics, it remains to be seen whether the same results arise if the two variables are tested among people living in developing nations which have significantly different socio-cultural factors than their western counterparts. Thus, these three factors presented a strong basis for investigating the relationship between the two constructs. In line with this approach, the purpose of this study was to assess the relationship between self control and well being in life, to research practical steps that individuals can readily apply in life to enhance their self control and to compare the results of the study with other studies in western developed countries and ascertain if similar results arise.

\section{LITERATURE REVIEW}

\section{Self-Control}

Self-control has been consistently defined as among human kind's most valuable assets (Hoffman, et al., 2013). Researchers exploring the construct have defined self control as an ability or capacity to manage, regulate, and overcome one's impulses, desires and potential actions (Hoffman, et al., 2013). A famous experiment conducted by psychologist Walter Mischel at Stanford University in the late 1960's and early 1970's demonstrated that four year old children who are able to display better self control then their peers in deciding whether to eat one marshmallow right away or two if they are able to wait for some time demonstrated that those children who controlled their emotional impulse to eat the marshmallow right away and eventually ate two marshmallows instead of one (after a time delay), outperformed their peers in a wide range of domains including academic success, life achievement, and well being, when they were assessed at regular intervals much later in life . Numerous benefits since those experiments have confirmed the strong relationship between a high degree of self control and greater academic and work achievement, better relationships, and lesser instances of delinquency or crime (Duckworth \& Seligman, 2005). Walter Mischel along with psychologist Janet Metcalf later proposed that the desire for instant pleasure or gratification arises from the brain's "cool system" and the ability to control oneself from the brain's "hot system." According to Pinker, (2011), the cool system refers to the limbic or emotional part of the brain, whereas the "hot system" involves the frontal lobes or the cognitive decision making part of the brain. This hypothesis was lent credence when McClure et al. (2004) conducted neuroimaging experiments to test this theory. The results clearly indicated that the frontal lobes were intimately involved in rational decision making and the ability to control emotional impulses. Moreover, neurologists have also discovered that patients with frontal lobe damage have extensive self control problems. They are infact, stimulus driven (Pinker, 2011) in that, they will automatically follow emotional impulses whether it be food, sex or other forms of instant gratifications. In some cases, patients with tumors in their frontal lobes were found to be exhibiting forms of inadequate self control. when they were operated upon and had their tumors removed, their symptoms of inappropriate behaviors also vanished, (Haidt, 2006). 
Thus, as psychologists have assumed since their earliest days of researching the phenomena, there actually is an internal struggle taking place between different parts of the brain when one's self control is being tested. This may also explain why, as several researchers have noted self control increases with age (Compton \& Hoffman, 2012). The frontal lobes continue to develop well into the late twenties (Pinker, 2011). This may be one of the key reasons for the majority of delinquent behavior found to be among age groups whose frontal lobes are still developing for e.g. those who are in their teenage years or early twenties.

Pinker, (2011) noted that, self control involves the ability to assess future states. For e.g. eating an excess of food today, leads to becoming fat later, cigarette smoking now, may lead to cancer tomorrow, unprotected sex in the moment, may lead to pregnancy, disease or jealously later, and so on. He hypothesizes that a seeming lack of self control in our world today may have resulted from people using a future assessment system that was weak and used a discounting rate of future that was appropriate for the time, for e.g. living in times when people died prematurely or did not have stable institutions or governing systems. Today, however, with the advent of modernity and development, established mechanisms are in place that allow individuals to appropriately place themselves in future scenarios and think of the consequences of their actions. According to Pinker, (2011), this also may have led to the general decline in violence over the centuries.

There is evidence that self control like a muscle can be fatigued by use. Baumeister, Vohs and Tice, (1994) developed the Strength model of self control which views self control as a limited resource. Commonly referred to as Ego Depletion, this model proposed that every time self control is utilized, it becomes weaker in subsequent trials. The researchers developed this model after conducting numerous experiments in which it was observed that participants would be good at self control in the first exercise and then get progressively worse at subsequent, seconds, third and fourth exercises. Further studies in the area, have corroborated these findings. Vohs, Baumeister, and Ciarocco, (2005) found that presenting a false or desired image to others or pretending to be someone else depletes self control. Similarly, seemingly complex tasks such as writing a convincing speech on why taxes should be raised (Pinker, 2011).

Self-control also has an important and often neglected component that is emotional in nature, that is, most if not all self control decisions involve some sort of emotion. Whether to indulge in that extra scoop of ice cream, have that one shot of liquor at a party, or sit in the car at the urging of friends at a drag car rally, all of these decisions involve emotion. According to Kool, Dillon and Sheepes, (2009), self-control in essence is the confluence of two types of self regulation: action and emotion. Thus, self control in part is self regulation that has a strong emotional component that could be furthered by improving one's emotional intelligence .

There is also accumulating evidence that self control may have a strong genetic base . Investigating the relationship between self control and genetics among siblings, Conolly and Beaver, (2013) concluded that genetic influences played a significant role in sibling levels of self control and delinquency, specifically, genetic factors accounted for between $31 \%$ to $92 \%$ of variance for self control among siblings (p. 724). This study confirmed earlier studies in the area which also reported similar results (Beaver et al., 2008; Beaver et. al., 2009). Pinker, (2011), also noted that it was highly likely that self control had a strong genetic base. "Self control is partly correlated with intelligence (with a coefficient of about 0.23 on a scale from -1 to 1 ), and the two traits depend on the same part of the brain, though not in the same way." This however, in no way means that biogenetic factors are the lone cause or the only elements 
involved in establishing self control. Factors such as environmental conditions also play a major role. There is also substantial evidence to support that self control can be enhanced through training, exercise, meditation and other forms of learning (Kool, Dillon and Sheepes, 2009; Ramel, Goldin, Carmona, \& McQuaid, 2004).

\section{Subjective Well Being}

Traditionally, happiness and wellbeing was viewed from one particular dimension, such as a) hedonic perspective (focus on pleasure), b) the Eudaimonic perspective (focus on fulfilling one's potential), and c) the engagement perspective (focus on activities). Researchers have suggested that a complete understanding of wellbeing requires more than one dimension (Compton \& Hoffman, 2012). With the gradual advent of positive psychology as a separate and complete science, wellbeing progressed to being viewed from multidimentional perspectives. In general, there are at present four established multidimensional theories of wellbeing (Compton \& Hoffman, 2012). Seligman, (2011) outlined his theory of wellbeing as PERMA, consisting of five essential elements: positive emotions, social support, engagement, meaning and achievement in life. Ryff, (1995) developed the Psychological Well-Being scale which consists of six factors: self acceptance, personal growth, positive relationships, autonomy, purpose in life, and environmental mastery. Deci and Ryan, (1985) formulated the self determination theory which postulated that three essential elements: competence, relatedness and autonomy are necessary for wellbeing. The fourth view relates to modes of fulfillment, Coan's, (1974, 1977) model includes efficiency, creativity, inner harmony, relatedness and self transcendence. A careful examination of the four multidimensional theories of wellbeing reveals certain common themes. Positive relationships figure prominently in all four models in some way.

Accomplishment or a personal sense of achievement is an inherent part of wellbeing, having a sense of purpose or meaning in life is also crucial as is feeling a sense of personal control over one's life or the environment. Carol Ryff's six-dimensional structure of wellbeing utilizes all four of these aspects. Ryff's $(1985,1995)$ model of wellbeing includes positive relationships, environmental mastery, purpose in life, autonomy, personal growth and self acceptance. Based on this model, Ryff, (1995) developed the wellbeing scale which has extensively been utilized for research purposes in positive psychology (Ryff \& Keyes, 1995). For the purpose of this study, the longer version of Carol Ryff's psychological wellbeing scale has been used, which has been found to have strong reliability and validity measures.

\section{Self-Control and Subjective Wellbeing}

There is ample evidence that various facets of subjective wellbeing, such as happiness, positive emotion, life satisfaction, achievement and good health are strongly associated with higher scores on self-control measures (de Ridder, Lensvelt-Mulders, Finkenauer, Stok, \& Baumeister, 2012). The premise behind these conclusions is that people who possess more self control are likely to be more motivated, achievement oriented and thus because of their accomplishments will be happier in life than those who have low self control (Moffitt et al., 2011). This assumption is supported by evidence that shows that self regulation conscientiousness and higher degrees of impulse control indeed do lead to higher motivation, accomplishment and better lifestyles later in life (Baumeister \& Vohs, 2007). A subset of good self control, Grit, has been found to be closely related to subjective wellbeing. People who are very self disciplined, who score high on measures of persistence, dedication, and determination are found to be better achievers, have more meaning and report more satisfaction in life (Compton \& Hoffman, 2012). Researchers have found that grit like self 
control increases with age, with people over 65 years of age scoring higher than other age groups (Seligman, 2011).

An investigation however is warranted between self control and an overall measure of wellbeing that is both extensive in nature and practical in its application. Such a study would provide a more accurate assessment of how the constructs relate with each other. Thus, this research study was an attempt to discover the links between self control and overall subjective wellbeing. Two additional goals of the paper were to assess how the results compared with similar studies in western nations and to investigate practical steps to improve self control if the results indicate that improving self control would positively affect well being in life. Based on these aims, the following research questions will be addressed by the study:

\section{Research Questions}

1. Can higher self control predict greater well being in life?

2. Are there significant differences between the association of the variables in reference to developed and developing countries?

3. If greater well being can be achieved through higher self control, (proved through a positive correlation between the variables), are there specific strategies that can be utilized to enhance self control?

\section{Hypothesis}

Null Hypothesis: The study would find no correlation between self control and well being. Alternate Hypothesis: The study would find a correlation between self control and well being.

\section{RESEARCH METHODOLOGY}

\section{Participants}

The research study assessed 100 students and faculty members from the department of management sciences at Bahria University, Islamabad. Bahria University is a chartered university fully recognized as a degree awarding institution by the Higher Education Commission, Islamabad, Pakistan. The ages of the participants ranged between 18 and 59. A stratified sampling strategy was used as it is the most appropriate technique in studies of this nature. All the research participants were treated in accordance with the Ethical Principles of Psychologists and Code of Conduct (American Psychological Association, 2002).

\section{Design}

A correlation research design was chosen for this study. Since, the primary objective of the study was to assess how the variables associate with each other, this was the obvious research design choice. Correlation designs are extensively utilized in studies that aim to uncover links between two or more constructs, or investigate the relationship between two or more sets of data (Creswell, 2008). 


\section{Instruments}

The scientific evidence has supported the notion that one's average level of happiness and life satisfaction are both relatively stable (Diener, 1994; McCrae, 2011), in fact studies have shown that self rating of subjective wellbeing remain consistent over several years. Ed Diener, (1998) a leading researcher of positive psychology stated that, to attain the best results, studies of wellbeing should include multiple indicators. Carol Ryff's $(1989,1995) 14$ item scale of psychological well being adequately fulfills this criteria .

The Ryff scale of wellbeing is comprised of 84 questions that assesses participants in six factors of well being. These are: autonomy in life, mastery of environment, personal development and growth, good social relationships, meaning in life, self acceptance and affirmation, autonomy, environmental mastery, personal growth, positive relations with others, purpose in life, and self-acceptance. The Ryff scale is an ideal instrument to assess wellbeing as it is an extensive scale covering most if not all dimensions of well being. It has also been the instrument of choice for numerous experiments relating to research involving life satisfaction and subjective well being. Previous research has confirmed the reliability and the validity of the Ryff scale of psychological wellbeing (Fernandes, Raposo, \& Teixiera, 2010; Ryff \& Keyes, 1995).

Self-control was assessed using the longer version of the Tangney, Braumeister, and Boone, (2004) scale. This is an extensive 36 item questionnaire that incorporates a broad spectrum of human behaviors. Importantly socio-emotional aspects of human self control are well covered within the scale. The authors of the scale have tested it utilizing classical test theory and have successfully concluded that the self reports on the scale accurately predict associations with wide ranging human behaviors such as well being, life satisfaction, anxiety, depression, emotional and relationship stability and conflict.(Tangney et al. 2004). Research testing the empirical validity of the scale have found it be valid, reliable and consistent (Hasford \& Bradley, 2011).

\section{Results}

Table 1: Correlation between wellbeing and self control

\begin{tabular}{|c|c|c|c|c|}
\hline \multicolumn{5}{|c|}{ Correlations } \\
\hline & & & Wellbeing & Self control \\
\hline \multirow{7}{*}{ Spearman's rho } & \multirow{4}{*}{ Wellbeing } & Correlation & 1.000 & $.583 * *$ \\
\hline & & Coefficient & & \\
\hline & & Sig. (2-tailed) & . & .000 \\
\hline & & $\mathrm{N}$ & 100 & 97 \\
\hline & \multirow{3}{*}{ Selfcontrol } & Correlation Coefficient & $.583 * *$ & 1.000 \\
\hline & & Sig. (2-tailed) & .000 & . \\
\hline & & $\mathrm{N}$ & 97 & 100 \\
\hline
\end{tabular}


Table 2: Descriptive Statistics

\begin{tabular}{|c|c|c|c|c|c|}
\hline \multicolumn{6}{|c|}{ Statistics } \\
\hline & & Age & Gender & Wellbeing & Self control \\
\hline \multirow[t]{2}{*}{$\mathrm{N}$} & Valid & 103 & 103 & 100 & 100 \\
\hline & Missing & 0 & 0 & 3 & 3 \\
\hline Mean & & 26.17 & 1.41 & 77.97 & -17.55 \\
\hline Median & & 24.00 & 1.00 & 77.50 & -17.00 \\
\hline Mode & & 22 & 1 & $63 a$ & $-20 a$ \\
\hline Std. Deviation & & 7.079 & .494 & 44.931 & 15.120 \\
\hline Sum & & 2696 & 145 & 7797 & -1755 \\
\hline
\end{tabular}

\section{DATA ANALYSIS}

The results showed a moderate positive correlation between wellbeing and self control, $\mathrm{r}=$ $.583, \mathrm{p}<0.05$. A Spearman's rho test was utilized for assessing the relationship between subjective well being and self control as both constructs are ordinal variables. The Spearman's rho test shows the strength of the association between the variables; statistics approaching +1.0 or -1.0 imply a correlation, whereas a statistic of 0.0 would indicate no relationship between the two variables (Creswell, 2011). In this case, a positive association between the two variables was clearly established.

\section{DISCUSSION}

The study comprehensively rejected the Null hypothesis which proposed that a positive correlation between self control and well being would not be established. The alternate hypothesis: which proposed that a positive correlation between self control and well being would be established was found as being valid. The correlation was found to be in the moderate range with an $\mathrm{r}=.583$, the result was significant. These findings were found to be consistent with earlier investigations in the field which assessed the relationship between self control and well being and found positive correlations between the two variables (de Ridder et al., 2011; Moffit et al., 2011; Vohs \& Faber, 2007). Thus, in response to the first research question: Can higher self control predict greater well being in life? The answer is in the affirmative, as proven by a positive correlation between the constructs and supported by earlier studies in the area. Although most studies, similar to this one have shown moderate positive correlations between self control and wellbeing (de Ridder et al., 2011), the question of exactly how strong the effect is and especially in what specific areas of well being, remains open, and further more in depth investigations will be required to ascertain those findings.

In response to the second research question: Are there significant differences between the association of the variables in reference to developed and undeveloped countries? The answer seems to be in the negative. The results of the study indicate that the findings are consistent with earlier studies researching the association between self control and well being that were conducted in highly developed nations in North America and Europe. Since, this study was conducted in Pakistan; a developing country with significant challenges in socio-cultural norms, economy, and political dimensions, the evidence seems to indicate that the relationship between self control and well being is consistent across national boundaries. This seems to support the notion that self control has a strong genetic base (Conolly and Beaver, 2013) and that positivity, a strong predictor of psychological well being in life is also partly genetic (Davidson, 2012; Haidt, 2005). 
The results of the study show that the third research question: If greater well being can be achieved through higher self control, (proved through a positive correlation between the variables), are there specific strategies that can be utilized to enhance self control? is in the affirmative. Substantial evidence indicates that self control can be enhanced through employing certain specific strategies and techniques (Hofmann,Baumeister, et al., 2012; Kool, Dillen \& Sheppes, 2009). Some of these strategies are included in the recommendations section. It is important to note that correlational studies of self control and subjective well being do not establish causal relationships. While it is possible that self control leads to higher subjective wellbeing, the reverse can also be true. Prior studies in subjective wellbeing have shown that well being can predict life outcomes: well being has been consistently reported to be associated with better health, higher income, marital success, and emotional stability (Diener \& Chan, 2011, Lyubomirsky, King \& Diener, 2005)

In conclusion, displaying self-control can lead to being happier in life. Self control is also crucial in regulating aggression and displays of hostility, thus although people with higher self control still engage in conflict, the frequency and self management is much better (Hoffman, et al., 2013). There could be several reasons for why self control could influence wellbeing in life. First, self-control allows us to focus on a particular goal or purpose, leading to achievement in life, second, self control allows people to have a greater sense of control over their lives, leading to an increase in a personal sense of control, third, self control can lead one to refrain from indulgent practices and instead focus on more purposeful aims in life, this translates to a greater sense of meaning, and fourth, self control in eating habits, exercising regularly and refraining from excess leads to better health and finally self control has been shown to lead to more positive emotion. Thus, self control is positively related not only to overall subjective wellbeing as a whole, but is also to its sub categories, although specific research in that domain remains outside the scope of this study.

\section{LIMITATIONS}

This study had certain limitations that could have skewed the findings. First, English was a second language for most participants, although, all the participants read and fully understood the language. The mode of instruction in the university where the study took place was also in English. Secondly, a majority of the participants of the study were students, and there may have been a tendency for some of them to provide what seem as "correct" answers. This is despite the students being advised that the questionnaires had no "right" or "wrong" answers. Third, the Ryff $(1985,1995)$ questionnaire on wellbeing is a extensive scale comprising 85 questions that can take between one hour to one and a half hour to complete. This relatively lengthy time may have resulted in some participants becoming fatigued and not concentrating fully on the questions being asked.

\section{RECOMMENDATIONS}

The findings of the study show that higher self control positively affects well being in life. The immediate question that arises from this conclusion relates to intentional efforts to enhance self control in life. Incorporating a higher degree of self control in life essentially means increasing skills and capacities towards self regulatory behavior. Some proven and relatively new techniques towards attaining this objective are:

1. Mindfulness Meditation, a meditative and introspective process in which people are encouraged to focus their attention towards the present moment (Kabat-Zinn, 1990) has been shown to be highly effective in self regulatory behaviors, especially in matters of emotional self-control (Ramel, Goldin, Carmona, \& McQuaid, 2004). An excellent way to incorporate 
mindfulness is to participate in a mindfulness training program. One such program is Mindfulness Based Stress Reduction (MBSR), this program is offered in medical institutions across the United States and elsewhere. Typically, MBSR comprises an 8-10 week course for groups of up to 30 participants who meet weekly for 2 to 2.5 hours for instruction and practice in mindfulness skills, together with discussion of stress, coping and homework assignments (Compton \& Hoffman, 2012).

2. Integrated body-mind training, in which trainees are coached in breathing processes, mental imagery, music and body relaxation has been shown to lower negative emotion, stress and illness, has also been found to enhance self regulatory behaviors and emotional self control (Tang \& Posner, 2009; Tang et al., 2007). Integrated body mind training can be developed by a consistently followed regimen of meditation, self hypnosis and breathing exercise's.

3. Physical Exercise, Research reveals that engaging in physical exercise releases the neurotransmitter: GABA, this in turn makes the body feel relaxed and enhances impulse control, a skill vital for self-regulatory behavior (Bradberry, 2012). Numerous studies have reported that regular exercise promotes a greater sense of accomplishment leading to enhanced self-control (McAuley et al, 2010). According to one study, even a moderate walk of 40 minutes thrice a week can lead to improved cognitive processes and help aging brains preserve more white matter (Voss et al., 2010).

4. Distraction, the phenomena of intense desire is similar to that of a wave in the ocean in that it tends to ebb and flow. When the desire or impulse is very strong, it is as if the current of the wave is at its peak. If one can wait it out, by distracting oneself, then the intensity of the desire passes and self control becomes much easier. The rule of thumb being avoiding or distracting oneself for at least 10 minutes (Bradberry, 2012).

5. Forgiving oneself, Feeling guilty and continuously punishing oneself for not living up to one's own self control standards is a sure fire way to decrease rather than increase self control. Research from neuroscience indicates that it is the chemistry of the brain rather than inherent character flaws that may be responsible for at least a part of our inability to control our impulses.

6. Look at the big picture, when faced with desire and impulse control situations, research indicates that it is helpful to see the issue or problem at hand from a larger viewpoint rather than a minute one. For example, being tempted with a tiramisu desert, one can exert self control by visualizing one's total body image and imagining how you will look if you continue with your diet, rather than when you are off it (Martinuzzi, 2013).

7. Increase your emotional intelligence, research shows that people high in EI have stronger thresholds for emotional self control leading researchers to develop a strong positive correlation between the two constructs. One fundamental aspect of EI is self awareness, which in particular seems to positively affect self-regulatory behavior (Martinuzzi, 2013). Another important aspect of EI is the ability to managing one's emotions. This includes the skills and abilities to self regulate mood, handle stress and rebound after setbacks. Being able to manage these crucial emotions plays a key part in emotional self control. According to Salovey, Meyer \& Caruso, (2002), high EI, is often correlated with moderate skills to regulate and control one's own emotions rather than with high emotional control. 


\section{REFERENCES}

Baumeister, R.F., Heatherton, T.F., \& Tice, D.M. (1994). Losing control: How and why people fail at self-regulation. San Diego, CA: Academic Press.

Beaver, K. M., DeLisi, M., Vaughn, M. G., Wright, J. P., \& Boutwell, B. B. (2008). The relationship between self-control and language evidence of a shared etiological pathway. Criminology, 46, 939-970.

Beaver, K. M., Schutt, J. E., Boutwell, B. B., Ratchford, M., Roberts, K., \& Barnes, J. C. (2009). Genetic and environmental influences on levels of self-control and delinquent peer affiliation: Results from a longitudinal sample of adolescent twins. Criminal Justice and Behavior, 36, 41-60.

Bradbery, T. (2012). The six secrets of self control. Forbes. Downloaded from http://www. forbes.com/sites/travisbradberry/2012/09/17/the-six-secrets-of-self-control on October $29^{\text {th }} 2014$.

Coan, RW. (1974). The optimal personality. New York: Columbia University Press.

Coan, R. W. (1977). Hero, artist, sage or saint. New York: Columbia University Press.

Compton, W. C., \& Hoffman, E. (2013). Positive psychology: The science of happiness and flourishing. Belmont, CA: Wadsworth.

Connolly, J, E., Beaver, M, K. (2013). Results From a Genetically Informative Analysis of Examining the Genetic and Environmental Influences on Self-Control. Journal of Interpersonal violence. doi: 10.1177/0886260513505209

Creswell, J. W. (2008). Educational research: Planning, conducting, and evaluating quantitative and qualitative research ( $3^{\text {rd }}$ ed.). Upper Saddle River, NJ: Pearson.

Davidson, R., \& Begley, S. (2012). The emotional life of your brain. New York, NY: Penguin Group.

Deci, E. L., \& Ryan, R. M. (1985). Intrinsic motivation and self-determination in human behavior. New York: Plenum.

De Ridder T. D, Lensvelt-Mulders, G., Finkenauer, C., Stok, F, M., \& Baumeister, F, R. (2011). Personality and social psychology review. 16(76). doi: $10.1177 / 1088868311418749$

Duckworth, A.L., \& Seligman, M. (2005). Self-discipline outdoes IQ predicting academic performance in adolescents. Psychological Science, 16, 939-944

Duckworth, A. L., Peterson, C., Mathews, M., \& Kelly, D. (2007). Grit: Perseverance and passion for long term goals. Journal of Personality and Social Psychology, 92(6), $1087-1101$

Fernandes, H.M., Vasconcelos-Raposo, J., \& Teixeira, C.M. (2010), Preliminary analysis of the psychometric properties of Ryff's scales of psychological well-being in Portuguese adolescents, The Spanish Journal of Psychology, 13 (2), 1032-1043. 
Goleman, D. J. (1995). Emotional Intelligence. New York: Bantam Books.

Haidt, J. (2005). The happiness hypothesis: Finding modern truth in ancient wisdom. New York, New York: Basic Books.

Hasford, J. \& Bradley, K.D. (2011). Validating Measures of Self Control via Rasch Measurement. Journal of Applied Business Research. 27(6), 45-56.

Hoffman, W., Luhmann, M., Fisher, R, R., Vohs, K, D., \& Baumeister, R, F. (2013). Yes,but are they happy? Effects of trait self-control on affective well-being and life satisfaction. Journal of Personality. 82(4):265-77. doi: 10.1111/jopy.12050.

Hofmann, W., Friese, M., \& Strack, F. (2009). Impulse and self-control from a dual-systems perspective. Perspectives on Psychological Science, 4, 162-176.

Kabat-Zinn, J. (1990). Full catastrophe living: Using the wisdom of your body and mind to face stress, pain and illness. New York: Delacorte.

Koole, L, S., Van Dillen, F Lotte., Sheppes, G. (2009). The Self-Regulation of Emotion. In Vohs, K. D., \& Baumeister, R. F. (Eds.). Handbook of Self-Regulation. Vol 2. New York: Guilford Press.

Martinuzzi, B. (2013). 8 easy ways to increase your self control. Leadership \& Management, CEO.com. Downloaded from http://www.ceo.com/leadership_and_management/8-easyways-to-increase-your-self-control/ on October 29th 2014.

McAuley, E., White, S., Rogers, L, Motl, R., \& Courneya, K. (2010). Mastery of goals lessons disease-related depression and fatigue. Psychosomatic Medicine, 72(1) Retrieved from http://www.news.illiniois.edu/news/09/1215physical.html

McClure, S.M., Laibson, D., Loewenstein, G., \& Cohen, J.D. (2004). Separate neural systems value immediate and delayed monetary rewards. Science, 306, 503-7.

Moffitt, T. E., Arseneault, L., Belsky, D., Dickson, N., Hancox, R. J.,Harrington, H., et al. (2011). A gradient of childhood self-control predicts health, wealth, and public safety. Proceedings of the National Academy.

Patton, J. H., Stanford, M. S., \& Barratt, E. S. (1995). Factor structure of the Barratt Impulsiveness Scale. Journal of Clinical Psychology, 51, 768-774.

Pinker, S. (2011). The better angels of our nature: why violence has declined. Penguin Group. New York: New York.

Ramel, W., Goldin, P. R., Carmona, P. E., \& McQuaid, J. R. (2004). The effects of mindfulness meditation on cognitive processes and affect in patients with past depression. Cognitive Therapy and Research, 28, 433.

Ryff, C. D., \& Keyes, C. L. M. (1995). The structure of psychological well-being revisited. Journal of Personality and Social Psychology, 69, 719-727. 
Salovey, P., Mayer, J.D., \& Caruso, D. (2002). The Positive Psychology of emotional intelligence. In C.R. Snyder and S.J. Lopez (Eds.), Handbook of positive psychology (pp. 159-171). New York: Oxford University Press

Seligman, M. E.P. (2011). Flourish: A new understanding of happiness and well-being. London, England: Nicholas Brealey.

Steger, M. (2009). Meaning in Life. In C.R. Snyder \& S. Lopez (Eds.), Oxford handbook of positive psychology (2nd ed., pp. 679-688). New York: Oxford University Press.

Tang, Y. Y., Ma, Y., Wang, J., Fan, Y., Feng, S., Lu, Q., et al. (2007). Short-term meditation training improves attention and self-regulation. Proc. Natl. Acad. Sci. U.S.A. 104, 1715- 1716 .

Tang, Y. Y., and Posner, M. I. (2009). Attention training and attention state training. Trends Cogn. Sci. 13, 222-227.

Tangney, J. P., Baumeister, R. F., \& Boone, A. L. (2004). High self-control predicts good adjustment, less pathology, better grades, and interpersonal success. Journal of Personality, 72, 271-322.

Vohs, K. D., \& Faber, R. J. (2007). Spent Resources: Self-Regulatory Resource Availability Affects Impulse Buying. Journal of Consumer Research Vol. 33 , 537-547

Vohs, K.D., Baumeister, R.F., \& Ciarocco, N. (2005). Self-regulation and self-presentation: Regulatory resource depletion impairs impression management and effortful self-presentation depletes regulatory resources. Journal of Personality and Social Psychology, 88, 632-657.

Voss, M, Prakash, R., Erikson, K., Basak, C., \& Chaddock, L, et al. (2010). Plasticity of brain networks in a randomized intervention trail of exercise training in older adults. Frontiers in Aging Neuroscience, 2, 32. Doi: 10.3389/fnagi.2010.00032 